\title{
Evaluation of Contamination Reduction on Gypsum Casts from Alginate Impressions Disinfected with Four Different Materials
}

\author{
Mohammad Pakdin ${ }^{1}$, Samira Soufiabadi ${ }^{2} \&$ Mahnaz Shahrakipour ${ }^{3}$ \\ ${ }^{1}$ School of Dentistry, Zahedan University of Medical Sciences, Zahedan, Iran \\ ${ }^{2}$ Oral and Dental Diseases Research Center, Department of Prosthodontics, School of Dentistry, Zahedan \\ University of Medical Sciences, Zahedan, Iran \\ ${ }^{3}$ Oral and Dental Diseases Research Center, Depatment of Biostatistics and Epidemiology, School of Health, \\ Zahedan University of Medical Sciences, Zahedan, Iran
}

Correspondence: Mohammad Pakdin, School of Dentistry, Zahedan University of Medical Sciences, Zahedan, Iran. E-mail: mohammad.pakdin@yahoo.com

Received: January 24, 2016 Accepted: April 12, 2016 Online Published: April 29, 2016

doi:10.5539/gjhs.v8n12p127 URL: http://dx.doi.org/10.5539/gjhs.v8n12p127

\begin{abstract}
Introduction: Infection control is one of the most important aspects in dentistry. According to the special features of dentistry, this profession can have a very important role in transmission of infection. This study was conducted by comparing the effects of four common disinfectants on the microbial contamination of alginate impressions and corresponding gypsum casts.
\end{abstract}

Methods \& Material: In this experimental study, eleven patients aged 20-30 years old were selected by convenience sampling method. Six alginate impressions for each patient were formed by 24-hour intervals. These sixty six alginate impressions were divided in six groups (control-no wash, wash with water, Micro10, 2\% Glutaraldehyde, 5.25\% Sodium hypochlorite and Deconex). Disinfection methods were done by spraying (except for glutaraldehyde group that was done by immersing method) and then the alginate impressions were placed in plastic bags for 10 minutes to prevent the evaporation of disinfectants. Sixty six gypsum casts were made from alginate impressions. Microbial swabs were collected from mid palatal region of alginate impressions and gypsum casts for all groups by dried sterile cotton. The swabs were cultured for bacteria by inoculation on Blood Agar at $37^{\circ} \mathrm{C}$ for 3 days. The positive cultures were counted and the data was analyzed by software SPSS21.

Results: The counting colonies of gypsum casts and alginate impressions which were disinfected by Micro10, $2 \%$ Glutaraldehyde, 5.25\% Sodium hypochlorite and Deconex were not statistically significant and meaningful.

Conclusion: All disinfectants used in this study, had the same and acceptable effect.

Keywords: gypsum casts, alginate impressions, disinfectants

\section{Introduction and Issue Explanation}

Infection control is one of most important subjects in dentistry, as there is high incidence of transmission of infection in this field. As it is not possible to identify all infected patients by taking medical history and doing physical examination the necessary precautions should be taken in dealing with all patients. In dentistry, infection can be transmitted in multiple ways, such as contact with blood, saliva, or other secretions (Leung \& Schonfeld, 1983). The blood is known as a microorganism carrier, and there is no case of contaminated blood to be safe. Saliva is another infective factor. Although saliva has some germicidal properties, it could be the carrier of microbes, viruses and even fungi (Merchant, Mcneight, Ciborowski, \& Molinari, 1984; Tan, Wolfaardt, Hooper, \& Busby, 1993; Drennon \& Johnson, 1990).

Disinfecting alginate impressions is inseparable aspect for preventing cross infections between the patients. Generally, cross infection control on alginate impressions is very concerning issue in dentistry. Most of alginate impressions are sent to the dental laboratory without sterilization and are contaminated with blood, saliva and food debris. It is reported that there were harmful bacteria on $67 \%$ of all dental impressions, rostrum, dentures, wax and other materials sent to laboratories. Therefore before impressions are filled with gypsum cast, all dental 
impressions should be disinfected. The common sterilization method is to spray disinfectant to the alginate impressions (Graig \& Powers, 2002).

\section{Method}

Eleven patients by 20-30 years old were selected in non-random convenience sampling method. This was approved by the committee of ethics in research with Human. On examination all of their present teeth were normal. They had no active decay, no active periodontal or dental disorders. After signing the cooperation agreement, medical history was taken and Oro-dental examinations was done. This experiment was done in Department of Prosthodontics, School of Dentistry Zahedan Medical University.

Six alginate impressions were made with proper stock tray for each patient and divided as following. Alginate impressions were made in 24-hour intervals to allow the normal flora of mouth to get back to normal (Haralur, 2012).

Group I (control): alginate impressions without any disinfectant solution or rinsing with water.

Group II: alginate impressions washed with water.

Group III: alginate impressions disinfected with Micro10 (10\%, Shimi Teb Azar).

Group IV: alginate impressions disinfected with $2 \%$ Glutaraldehyde (Behsa Co., Iran).

Group V: alginate impressions disinfected with 5.25\% Sodium hypochlorite (Paksan Co., Iran)

Group VI: alginate impressions disinfected with Deconex (Irenic Co. Switzerland).

Alginate impressions were numbered in each group. After molding, all alginate impressions (except control group) were washed with $22^{\circ} \mathrm{C}$ tap water for 30 seconds and the remaining water was removed by gentle air spray to avoid drying. The sterilization method had been used for group III, V and VI by spraying the disinfectants towards the alginate impressions from $20-\mathrm{cm}$ distance. Group IV, was immersed in the solution (because of possible toxic effects of Glutaraldehyde if sprayed). Then alginate impressions were kept in plastic bags for 10 minutes to prevent the evaporation of disinfectants (according to recommendation of ADA, 1991). Bacterial swabs were collected from mid palatal regions of all alginate impressions (Figure 1). Then the gypsum casts (type III) were made from alginate impressions and numbered accordingly. The dental casts were removed from their alginate impressions after one hour. There were 66 alginate impressions and 66 gypsum casts were made from them which make it totally 132 samples. Bacterial swabs were recollected from mid palatal regions of gypsum casts (Figure 2).

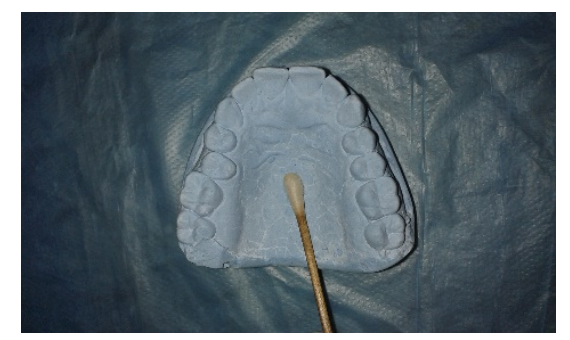

Figure 1. Swabbing from alginate impression

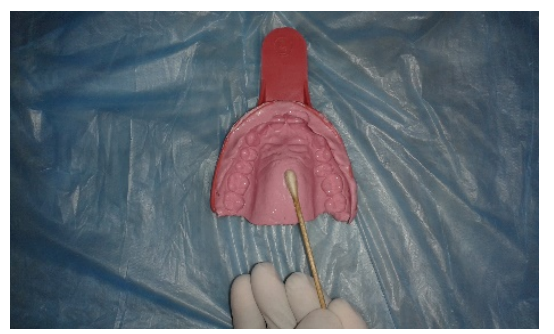

Figure 2. Swabbing from gypsum cast

Bacterial culture was done by zigzag motion of swab on Blood Agar plate (Figure 4). The plates were divided in three parts used for three different samples (Figure 3). These plates were kept in incubator for 3 days at $37^{\circ} \mathrm{C}$. 


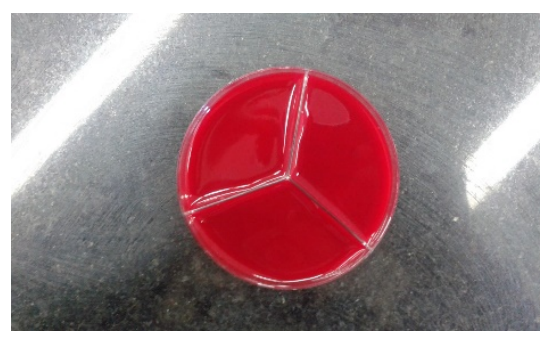

Figure 3. Blood Agar plate for bacterial cultures

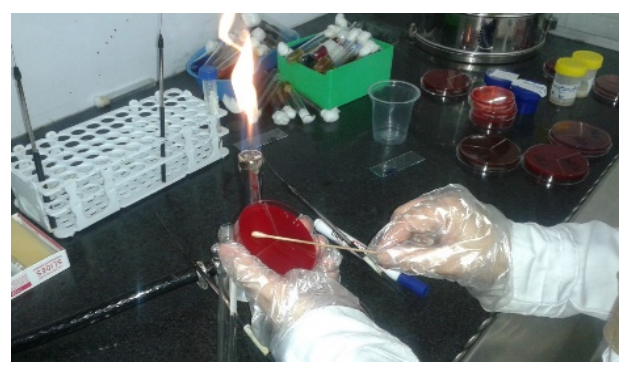

Figure 4. Microbial culturing

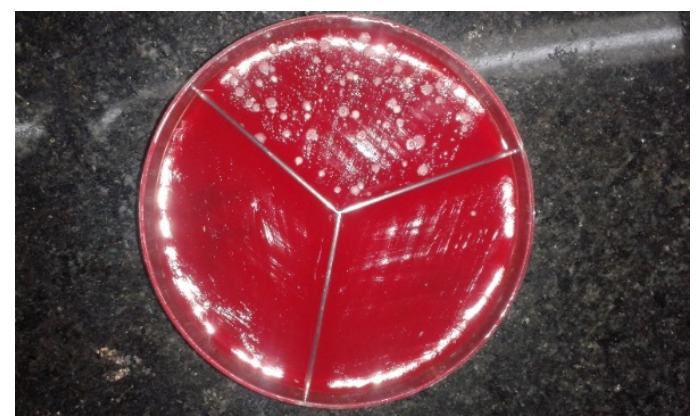

Figure 5. Colony growth

Then the number of positive cultures obtained from the alginate impression surfaces was compared with that of gypsum casts in each group separately (Figure 5). The data was analyzed by SPPS21 software. Procedure of culturing and reading was done in Medical Microbiology Department of Zahedan Imam Ali Hospital.

\section{Results}

This study was conducted to examine the effect of four common disinfectants on bacterial growth on surface of alginate impressions and related gypsum casts in six different groups. The Number of cases with positive bacterial culture out of total eleven patients' with corresponding percentages and standard deviation is shown in following table.

Table 1. Comparison of positive bacterial cultures of all samples in different groups

\begin{tabular}{lllllll}
\hline & Group I & Group II & Group III & Group IV & Group V & Group VI \\
\hline Alginate impression & $1(9.1 \%)$ & $2(18.2 \%)$ & No growth & No growth & No growth & No growth \\
Gypsum cast & $3(27.3 \%)$ & $3(27.3 \%)$ & No growth & No growth & No growth & No growth \\
P-value & 0.269 & 0.611 & ---- & ---- & ---- & --- \\
\hline
\end{tabular}

According to above results, out of eleven samples in control group there was one sample with positive bacterial culture from the surface of alginate impressions and three positive samples from gypsum casts. This increase 
number of bacteria could be due to contaminated lab environment and/or the gypsum cast by itself.

In water washed group there were two positive cultures in alginate impressions in compare to three positive cultures in gypsum cast. This shows that washing alginate impressions with water is not effective for decreasing bacterial count. There was no meaningful difference between alginate impressions and gypsum casts in group I and II because P-value of them is more than 0.05 .

There were no report of any colony growth in alginate impressions and related gypsum casts which were sterilized with four common disinfecting solutions (group III to VI). The negative cultures from cast surface are due to the effect of disinfectant solution which is carried from the surface of alginate impressions to the gypsum cast. This shows the positive and equal effects of these four disinfection on sterilization.

\section{Review of Literature}

According to World Health Organization report on disinfecting the impression in 1973, it was recommended immersing impressions in $2 \%$ Glutaraldehyde or Sodium hypochlorite solutions with $1000 \mathrm{ppm}$ rate chlorine for one hour because all impressions especially those with a high risk are potentially infective and should be treated in the same way.

As Westerholm et al. reported the Sodium hypochlorite with the maximum power (5.25\%) was the most effective disinfectant on alginate; especially, when it is sprayed. The same result was obtained by using Glutaraldehyde solution. But other disinfectants had no similar effect (Westerholm, 1992).

Tan H.K and et al., in this study evaluated the effects of disinfection time (10, 30, and 60 minutes) on the surface quality of stone casts poured against an alginate impression material (Jeltrate). Five antimicrobial agents were tested: Sporicidin, Sodium hypochlorite, and Iodophor for spray; and Sporicidin cold sterilization solution and Cidexplus glutaraldehyde solution for immersion. Impressions, flushed with water and stored for $0,10,30$, and 60 minutes before pouring, served as untreated controls. On completion of the disinfection treatments, the impressions were rinsed and poured in Velmix stone. The effects on cast surface were evaluated under a stereomicroscope by three experienced raters. A 1-to-4 scoring system was developed to rate the surface quality in terms of smoothness and detail reproduction. Both immersion disinfectants proved to be unacceptable for treating alginate impressions. The mean scores of other disinfectant-time combinations were compared with the use of the Tukey-Kramer method with a $95 \%$ confidence interval. The results indicated that treatment time had statistically significant effects on the quality of cast surface in Sporicidin spray, Sodium hypochlorite, and untreated control groups but not in the Iodophor spray group (Tan, Wolfaardt, Hooper, \& Busby, 1993).

$\mathrm{Li} \mathrm{Xw}$ et al. examined the germicidal power of Glutaraldehyde. Their experiment showed that $2 \%$ Glutaraldehyde solution destroyed $99.99 \%$ of all Staphylococcus aureus at $20^{\circ} \mathrm{C}$, and $1 \%$ Glutaraldehyde solution destroyed $99.99 \%$ of E.coli (Escherichia coli) both after two minutes. The antiseptic solution without any dilution was able to destroy HBsAg virulence after 5 minutes. Its non-diluted and 50\% diluted solution was able to destroy Bacillus subtilis spores completely after 35 and 45 minutes, respectively (Li, 1996).

In 2001, Acosta Gio A. et al. conducted a study to compare the sporicidal activities of Glutaraldehyde with Benzalkonium chloride on Bacillus subtilis spores. Their result showed that Micro10 could not kill Bacillus subtilis spores even after 15 hours while 2\% Glutaraldehyde destroyed all spores after 10 hours. These results confirmed that Micro10 has no sporicidal effects and it could not be used to sterilize the medical and dental accessories (Acosta-Gio, Herrero- Farias, \& Mata-Portuguez, 2001).

There is an in vitro study by Dr. Abbas Shakeri and Javad Sultanpoor which examined the antimicrobial effects of Micro10 solution. This disinfectant with different concentrations showed to be $100 \%$ bactericidal and fungicidal. This disinfectant is known as an intermediate disinfectant by killing Mycobacteria tuberculosis (TB) and by exterminating the Bacillus subtilis spores known as high level disinfectant. According to results of the study, it was found it had wide range and lasting effect and also had virucidal effect (Shakeri \& Soltanpoor, 2002).

In a study, Dr. Kamila Alijani et al. Compared antiseptic effects of $0.5 \%$ Sodium hypochlorite and $2 \%$ Glutaraldehyde on prosthetic impressions. They didn't find any difference between antiseptic effects of these solutions (Alijani, 2003)

There is another study by Dr. Arefeh Eftekhari to examine Micro10 effects on Bacillus subtilis in two stages: vegetative stage and sporulation stage and the antiseptic effects of Micro10 were shown after 24-hour interval (Eftekhari \& Fallah, 2004).

In another study the disinfecting effect of different concentrations of Sodium hypochlorite on alginate 
impressions, was conducted by Dr. Maryam Memarian and Ahmad Azimnejad in 2005. In this experimental study, they used gram-positive and gram-negative bacteria and disinfectant was domestic hypochlorite $5.25 \%$ concentration called witex. After preparing bacterial suspension and different dilutions of Sodium hypochlorite, the micro dilution method had been used to identify the effective Sodium hypochlorite concentration in certain time. The findings revealed that all studied germs related to the irreversible hydrocolloid impressions were destroyed after 2 minutes by using 0.6\% Sodium hypochlorite solution (Memariyan \& Azimnezhad, 2005).

Hussain et al. studied the effect of disinfection of irreversible hydrocolloid impressions on the properties of gypsum casts type III. The results revealed that both 'Perform ID' and 'Dimenol' affect the hardness of gypsum type III, but 'Impressi V' has no effect (Hussain, Tredwin, Nesbit, \& Moles, 2006)

In 2007, Dr. Behnaz Ebadian et al. conducted a study for evaluation of disinfecting effect of $0.5 \%$ Sodium hypochlorite and $2 \%$ Glutaraldehyde on Heat-cure acrylic resin with two type bacteria namely Streptoccus viridans and Bacillus subtilis. The result indicated that both disinfectant solutions eliminated Streptoccus viridans after 30 minutes but could not eliminate Bacillus subtilis until 4 hours immersion time. They also found out that there was no difference between disinfecting ability of $0.5 \%$ Sodium hypochlorite and $2 \%$ Glutaraldehyde solutions (Ebadian, Poorsina, \& Saghaei, 2007).

There is a study conducted by Ahmad Ghahremanloo et al. to examine three different disinfection materials on alginate disc by immersion and spray methods. In this study, the Sodium hypochlorite was more effective than Deconex and Senosil D2. They also reached to conclusion that spraying is better than immersing method because alginate has hydrophilic property (Ghahremanloo, 2011).

In 2012, Haralur et al. studied the effect of two chemical disinfecting solutions: Sodium hypochlorite (1:10) and Iodophor on alginate impressions with their effects on survived bacterial numbers in gypsum casts. They produced four alginate impressions for each dental patient which the first group was not rinsed or disinfected, second group washed with merely water, third group disinfected by spraying Sodium hypochlorite (1:10) and the last group disinfected with Iodophor (1:213). All gypsum casts (gypsum type III) were made from alginate impressions. The sampling of all impressions and gypsum casts from mid palatal region were cultured. Counting bacterial colonies had been done from incubation in blood agar at $37^{\circ} \mathrm{C}$ after 3 days. The data was examined by one-way NOVA method with $p$-value $\leqslant 0.05$. The results showed that there were more bacterial colonies in groups I and II than groups III and IV. The number of bacterial colonies in alginate impressions and gypsum casts that were disinfected by Sodium hypochlorite (1:10) and Iodophor (1:213) were 0.18 and 0.82 respectively. Result of their study shows that alginate impressions as well as dental casts without disinfection carry a lot of bacteria over them. They emphasize that washing of alginate impressions only with water is not an efficient disinfection method. So it is important for dentists to disinfect alginate impression before sending it to laboratory. They also concluded that Sodium hypochlorite was a better disinfectant than Iodophor for disinfecting alginate impressions (Haralur, 2012).

Based on an in vitro study done on Deconex product in Pasture Institute of Iran, It is considered as powerful disinfectant (high level) and was introduced as 100\% mycrobactericidal (Anonymous, 2014).

The bactericidal effect of Deconex solution was also shown by in vitro studies done in Imam Khomeini Hospital (Anonymous, 2014).

From all above studies we may reach to the conclusion that mainly two groups of disinfectants have been used.

The first group being: $5.25 \%$ Sodium hypochlorite and $2 \%$ Glutaraldehyde (there were no differences between these two disinfectants) and second group: Micro10 and Deconex (they were similar and in the same level). It seems that the first group was more powerful and effective than second group.

\section{Conclusion}

Alginate impression and gypsum cast carry lots of bacteria over them if not disinfected. Our study shows that washing with water alone is not enough to kill bacteria. So it is necessary to disinfect alginate impressions before sending them to dental laboratory. We used four disinfectants namely Micro10, 2\% Glutaraldehyde, 5.25\% Sodium hypochlorite and Deconex. After using these disinfectants on alginate impressions no single positive bacterial culture was found on alginate impressions or related gypsum casts (type III). So we fill they can be used as an efficient disinfectant for disinfecting alginate impressions.

\section{Acknowledgements}

The authors appreciate the cooperation and support of the staff of Prosthodontics Department of School of Dentistry and Department of Biostatistics and Epidemiology of School of Health, Zahedan University of Medical 
Sciences and Medical Microbiology Department of Zahedan Imam Ali Hospital.

This paper is a summary of my approved thesis with the same tittle and number 7537 which was done in above departments of Zahedan University of Medical Sciences, Iran in 2015-2016.

\section{Competing Interests Statement}

The authors declare that there is no conflict of interests regarding the publication of this paper.

\section{References}

Acosta, G. E., Herrero, F., \& Mata-Portuguez, V. (2001). Benzalkonium chloride: Unacceptable to sterilize or disinfect medical or dental instruments. Salud Publica Mex, 43(6), 570-573.

Alijani, K. (2003). Compared antiseptic effects of 0.5\% Sodium hypochlorite and 2\% Glutaraldehyde on prosthetic impression (Unpublished doctoral dissertation). Azad Islamic University, Tehran, Iran.

Deconex antiseptic products guidelines. (2014). Borer chemie company, Tehran, Iran.

Drennon, D., \& Johnson, G. (1990). The effect of immersion disinfection of elastomeric impressions on the surface detail reproduction of improved gypsum casts. $J$ Prosth Dent, 63, 233-41. http://dx.doi.org/10.1016/ 0022-3913(90)90111-O

Ebadian, B., Poorsina, F., \& Saghaei, S. (2007). Evaluation of disinfecting effect of 0.5\% Sodium hypochlorite and 2\% Glutaraldehyde on heat-cure acrylic resin. J Mashhad Dent Sch, 31(3), 217-22. Iran.

Eftekhari, A., \& Fallah, F. (2004). Evaluation of the effect of sterilization of Micro10 solution on critical equipments. Tehran, Iran.

Ghahremanloo, A., Sadeghian, A., \& Bidi R. (2011). Effect of three different disinfection materials on alginate disc by immersion and spray methods. J Babol Univ Med Sci, 13(3). Iran.

Graig, R. M., \& Powers, J. (2002). Restorative Dental Materials (11th ed.). St. Louis, U.S.A.

Haralur, S. B., Al-Dowah, O. M., Gana, N. S., \& Al-Hytham, A. (2012). Effect of alginate chemical disinfection on bacterial count over gypsum cast. $J$ Adv Prosth, 4, 84-8. http://dx.doi.org/10.4047/jap.2012.4.2.84

Hussain, S., Tredwin, C., Nesbit, M., \& Moles, D. (2006). The effect of disinfection on irreversible hydrocolloid and type III gypsum casts. Eur J Prosth Restor Dent, 14(2), 50-4.

Leung, R., \& Schonfeld, S. E. (1983). Gypsum casts as a potential source of microbial cross-contamination. $J$ Prosth Dent, 52, 877-9. http://dx.doi.org/10.1016/0022-3913(83)90503-6

Li, X., Li, O., \& Li, T. (1996). Experimental observation on microbicidal activity of a complex Glutaraldehyde disinfectant. Zhonghu Liu Ing Bing Xue Za Zhi, 17(5), 292-295.

Memariyan, M., \& Azimnezhad, A. (2005). The effect of different concentrations of Sodium hypochlorite to disinfect alginate impressions. J dent school, shahid beheshti Univ Med Sci, 23(3), 515-20. Tehran, Iran.

Merchant, V. (1991). Updates on disinfection of impressions, prosthesis, and casts. Guidelines recommended by American Dental Association [ADA]. J Calif Dent Assoc.

Merchant, V., Mcneight, M., Ciborowski, C., \& Molinari, J. (1984). Preliminary investigation of a method for disinfection of dental impressions. J Prosth Dent, 52, 877-9. http://dx.doi.org/10.1016/S0022-3913 (84)80024-4

Shakeri, A., \& Soltanpoor J. (2002). Evaluation of quality and effect of micro10. J Islamic Dent Assoc, 13, 7-21. Iran.

Tan, H., Wolfaardt, J., Hooper, P., \& Busby, B. (1993). Effects of disinfecting irreversible hydrocolloid impressions on the resultant gypsum casts. J Prosth Dent, 69, 250-7. http://dx.doi.org/10.1016/0022-3913 (93)90101-S

Westerholm, H. S., Bradley, D., \& Schwartz, R. S. (1992). Efficacy of various spray disinfectants on irreversible hydrocolloid impressions. Inter J of Prosth, 5(1), 47-54.

\section{Copyrights}

Copyright for this article is retained by the author(s), with first publication rights granted to the journal.

This is an open-access article distributed under the terms and conditions of the Creative Commons Attribution license (http://creativecommons.org/licenses/by/3.0/). 